\title{
Sección bibliográfica
}

\author{
Notas
}

Enrique Astorga LiRa. Mercado de trabajo rural en México. La mercancía humana, ERA, México, 1985, 127 pp., Col. "Problemas de México".

En este ensayo el autor coloca al hombre "como epicentro de todas las relaciones productivas y sociales que surgen en el campo". Encuentra que existen diversos modos que sirven para incorporar a los campesinos al servicio del capital, a través de mecanismos que define como las etapas que recorre el campesino para vender su fuerza de trabajo, los canales y niveles que son los conductos usados y el espacio para que el peón realice sus labores.

La narración que hace el autor de las vicisitudes que sufren los peones está basada en trabajo de campo y describe minuciosamente los pasos que siguen los campesinos para lograr contratarse como peones; en forma paralela, detalla los procedimientos que siguen los patrones para allegarse fuerza de trabajo campesina barata y temporal. Asimismo delinea las condiciones de trabajo y de vida a que están sujetos los campesinos durante las jornadas de labor fuera del minifundio.

Uno de los capítulos está dedicado a especificar la influencia que ha. venido ejerciendo el capital trasnacional en la demanda de fuerza de trabajo al actuar sobre la esfera productiva y la de circulación de la agricultura mexicana.

Posteriormente, en la parte central del ensayo, el autor introduce una distinción entre la economía campesina y la economía empresarial basada en los diferentes productos que ambas lanzan al mercado; la economía campesina produce la "mercancía" fuerza de trabajo en forma de peones, la economía empresarial envía productos al mercado. La interdependencia de ambas se encuentra en la producción por parte de una y la utilización por parte de la otra de la fuerza de trabajo del peón.

Es en esta forma como el peón se convierte en medio para producir mercancías; el hombre queda a disposición de las necesidades de los cultivos.

En este contexto, la característica que distingue a la economía campesina, que a su vez constituye su objetivo principal y el motivo de su persistencia como tal, es la producción social de peones. Por ello, el autor 
afirma que el autoconsumo no es el fin de la actividad productiva del minifundio, sino un medio para producir peones y sirvientas.

M.E.M.C

Paul Bairoch . De Jéricho à Mexico. Villes et économie dans l'histoire, Gallimard, París, 1985, Col. Arcades.

En este libro Bairoch ofrece una síntesis de la historia de la urbanización y al mismo tiempo un análisis de los vínculos entre la ciudad y la economía a través de diferentes periodos y sociedades.

Conforman el libro 30 capítulos distribuidos en cuatro apartados. El primero aborda los orígenes del fenómeno urbano, contiene reflexiones sobre la simultaneidad y multiplicidad de la "invención" o adopción de la agricultura, y sobre la interacción de la misma y la emergencia de la ciudad.

El segundo apartado lleva al lector a un recorrido histórico del siglo $\mathrm{V}$ al XVIII por lo que el autor denomina la Europa tradicional; se señalan sucesos que determinan cambios como la emergencia del cristianismo, las ciudades mercantiles de Italia, el descubrimiento del nuevo mundo. Esta sección termina con un análisis de las relaciones entre la urbanización y el desarrollo anteriores a la revolución industrial.

El autor pasa después a describir el proceso de transformación e interacción de la ciudad y el desarrollo del mundo occidental que se da con el advenimiento de la revolución industrial. Se tratan cuestiones referentes a la vinculación entre la ciudad y el inicio de la revolución industrial, la industrialización y la ciudad, la innovación técnica y la ciudad, las nuevas formas de transporte y la ciudad, etcétera.

Por último, la cuarta parte se dedica al análisis de la historia urbana de las sociedades no occidentales del siglo XVI al XX, abarcando el periodo colonial y el subdesarrollo posterior, no sin antes estudiar la historia, la evolución y las características de la vida urbana anterior a la colonización. Después se analizan las consecuencias de la colonización sobre el mundo urbano de Asia, Medio Oriente, África negra y América Latina. El autor también argumenta sobre el problema crucial del subdesarrollo y la inflación urbana del Tercer Mundo, hechos que considera sin precedentes en la historia de la humanidad.

En cada uno de estos apartados se revisan temas fundamentales mediante la presentación de las tesis de los más destacados estudiosos y el autor plantea su opinión y enfoque dejando que el lector encuentre su propio camino. Así, por ejemplo, somete a discusión las cuestiones sobre cuáles son los vínculos entre la agricultura y los orígenes de la urbanización, 
sobre si la ciudad fue un elemento determinante en el advenimiento de la revolución industrial, sobre cuándo y cómo surgieron las ciudades y sobre aspectos metodológicos generales como localización, jerarquía, tamaño y funciones económicas de las ciudades, entre otras.

M.E.M.C.

IAN Burton, W. KaTES, y GibBeRT F. White. The Environment as Hazard, Oxford University Press, Nueva York, 1978, 240 pp.

En esta publicación se plantea la interrogante sobre si el medio ambiente presenta actualmente mayores riesgos para la humanidad que en otras épocas. Para presentar un panorama global, los autores resumen los resultados de diversas investigaciones que se han realizado en diferentes países.

Algunas cifras globales indican que, a pesar de que el número promedio de desastres ha permanecido prácticamente constante, las pérdidas de vidas humanas, la riqueza material destruida así como la extensión de las áreas afectadas se han incrementado significativamente en los periodos recientes.

Una vez que definen los conceptos de desastre y riesgo, y delinean los patrones de respuesta humana ante las catástrofes naturales, los autores presentan ejemplos de situaciones de desastre, ofrecen explicaciones de los hechos y de la forma en que se resolvieron, comparando casos ocurridos en países desarrollados y subdesarrollados.

Posteriormente se realiza una evaluación de las medidas que adoptan los individuos y los países para prevenir los grandes desastres naturales, qué volumen de gastos se involucran y cuál es la experiencia que se puede derivar. Ya en ese terreno, se trata de encontrar una respuesta adecuada sobre el tipo de medidas preventivas que pueden implantar los países en forma individual y el tipo de medidas que podría adoptar la comunidad internacional en forma conjunta.

La conclusión general señala que, aunque a largo plazo sería posible lograr un medio ambiente con menores riesgos gracias a la adopción de las medidas adecuadas, en el corto plazo el proceso requerido para lograr un medio ambiente más favorable es costoso y díficil de alcanzar.

M.E.M.C. 
TEResita De BARBIERI. Mujeres y vida cotidiana, SEP/FCE, México, 1984, Col. SEP 80, núm. 60.

La autora de este libro transita caminos no trillados en la búsqueda de la metodología adecuada para estudiar la condición femenina. La estrategia de investigación es el análisis de la vida cotidiana de las mujeres mexicanas: ¿qué hacen?, ¿cómo transcurre su vida?, ¿cómo distribuyen su tiempo?

Mediante entrevistas realizadas a 34 mujeres pertenencientes a sectores medios y obreros de unidades domésticas nucleares y extendidas, De Barbieri penetra hábilmente en los avatares de su vida diaria: ¿qué leen?, ¿cuál es su proyecto de vida?, ¿qué piensan sobre la liberación femenina, la participación política y social?

Particularmente interesante resulta el capitulo en el cual se hace el resumen e interpretación de los datos y se señalan las diferencias y semejanzas entre las concepciones y labores de las mujeres de los sectores medios y obreros.

Como resultado de ese análisis se concluye que el común denominador de las actividades femeninas es el trabajo doméstico, realizado por todas y cada una de las entrevistadas con mayor o menor intensidad. A partir de esa constante, se plantea una argumentación sobre el trabajo doméstico e incluso se propone una tipología. Se trata de un trabajo cor:creto que no se valoriza: se tiene que ampliar, modificar, adaptar a condiciones y límites impuestos, exógenamente materializados en el salario del varón. ¿Quién o quiénes se benefician del trabajo doméstico? La respuesta trata un tema sin duda polémico: los que compran la fuerza de trabajo de las unidades domésticas son quienes, en última instancia, se apropian del trabajo doméstico.

Esta investigación representa un intento por abandonar el mero discurso sobre la subordinación de la mujer, para indagar empíricamente cuál es la condición femenina en una clase social y tipo de unidad doméstica dada. Por otra parte, como señala la investigadora, los límites impuestos por los objetivos planteados impidieron que tratara con profundidad temas que apenas señala. En el libro se encuentran hipótesis y temas de estudio que al desarrollarse coady!ıvarán al conocimiento de la condición femenina. 
Aprodicio A. Laquian. Vivienda básica. Políticas sobre lotes urbanos, servicios y vivienda en los países en desarrollo, Centro Internacional de Investigaciones para el Desarrollo, Ottawa, $1985,174 \mathrm{pp}$.

Esta publicación presenta el informe sobre vivienda básica y la evaluación de programas de mejoras comunitarias y lotes urbanos realizados en cuatro países: El Salvador, Filipinas, Senegal y Zambia, patrocinados por el Centro Internacional de Investigaciones para el Desarrollo (corporación públicá canadiense creada en 1970) y el Banco Mundial.

En las ciudades de los países subdesarrollados creció la población vertiginosamente al recibir a millones de nuevos habitantes, en su mayoría emigrantes del campo, que a su vez se multiplicaron al correr de los años debido a las altas tasas de natalidad. Uno de los problemas más apremiantes planteado a los gobiernos de esos países ha sido el de proveer de vivienda y servicios básicos a los pobres de las ciudades.

El informe describe los diversos momentos que han seguido las políticas de vivienda implantadas en los países subdesarrollados y concluye que ante el fracaso de los desalojos y de los planes de vivienda terminada, las autoridades empezaron a ensayar nuevos métodos entre los que se encuentra el de vivienda básica y lotes con servicios.

El lector interesado en estos temas encontrará respuesta a las principales interrogantes sobre costeabilidad, auto-ayuda y ayuda mutua, reducción de costos, consolidación de viviendas, códigos y normas de construcción, recuperación de costos, y por último efecto de los proyectos sobre el desarrollo de la comunidad y de las áreas circunvecinas de las ciudades del Tercer Mundo consideradas.

M.E.M.C.

JACQUes VALuIN y AdÁN LóPez (eds.). La Lutie contre la Mort. Influences de politiques sociales et de politiques de santé sur l'évolution de la mortalité, Presses Universitaires de France, París, 1985, Col. Travaux et documents, cahier 108.

Se publican en este documento las reflexiones y los trabajos presentados en un seminario internacional llevado a cabo en París en febrero de 1983 con el objeto de examinar las relaciones entre la tecnología médica, los sistemas de salud y las políticas económicas y sociales por una parte, y la evolución de la mortalidad por otra.

Eil libro consta de 25 capítulos ordenados en tres grandes partes. El 
primer apartado presenta la discusión y evaluación de los programas verticales -aquellos que tienen como objetivo erradicar una enfermedad particular- y los programas de salud primaria que involucran acciones tendientes a lograr un mejoramiento general del estado de salud de una población en los países en desarrollo.

La segunda parte, dedicada a los programas de salud de los países desarrollados, analiza la lucha contra las enfermedades cardiovasculares, el cáncer, el tabaquismo y las muertes violentas, teniendo sólo un tema común con respecto a la experiencia de los países en desarrollo: la mortalidad infantil. Sin embargo, en este caso se enfoca el objetivo de su virtual abatimiento mediante programas de atención pre y posnatal.

Los capítulos que conforman estos dos apartados muestran la amplitud y complejidad del tema central de la publicación; en muchos de ellos se señalan propuestas de investigación que deberían realizarse tanto para enriquecer los aspectos teóricos como para lograr una mejor toma de decisiones en cuanto al diseño y aplicación de programas.

La tercera parte está dedicada a la descripción de las políticas que han. aplicado los dos grupos de países y a la evolución de la tasa de mortalidad, sus niveles y causas. Entre ellos se presentan casos que pueden resultar paradójicos: Costa Rica y China, por ejemplo, a pesar de no tener grandes avances en desarrollo económico, han logrado cambiar el perfil de la mortalidad y la morbilidad. Asimismo, en el grupo de países desarrollados destacan los casos de Japón que ha obtenido un éxito sin precedente en sus políticas de salud; de Francia, cuyo mejoramiento en la salud se ha debido más al incremento en el nivel de vida que a los programas sanitarios, y de Polonia, que es un caso particularmente inquietante pues la reversión en la tendencia de su mortalidad parece ser representativa de la evolución que se está dando en los países europeos de economía centralmente planificada.

Las conclusiones globales que pueden extraerse son: que es difícil señalar los factores determinantes de la declinación de la tasa de mortalidad; que los sistemas de salud y la tecnología han sido sin duda factores muy importantes, pero su aplicación requiere de un ambiente político social favorable a fin de que su eficacia sea mayor y mejores los resultados que se obtengan. En los países en desarrollo todavía se puede abatir la tasa de mortalidad, sobre todo la infantil, sin necesidad de recurrir a fuertes gastos presupuestales, a condición de que se cuente con un personal médico involucrado y conocedor de la situación de la salud de toda la población, y que se implementen programas integrados de salud complementados con una política económica y social que busque favorecer a las grandes masas de población que permanecen marginadas. 